\title{
L'estat actual de l'accés obert
}

\section{El estado actual del acceso abierto}

\section{The current status of open access}

\author{
Autor \\ Ignasi Labastida i Juan \\ orcid.org/0000-0001-7030-7030 \\ CRAI Universitat de Barcelona \\ ilabastida@ub.edu
}

Resum: Fa uns anys l'accés obert semblava una opció minoritària que no acabava d'establir-se com a alternativa per difondre els resultats de la investigació i avançar en la carrera acadèmica. El suport decidit de les institucions que financen la recerca ha estat cabdal perquè avui l'accés obert sigui una alternativa viable a l'hora de publicar i a més sembla que es consolida com l'opció del futur. Tanmateix encara hi ha alguns dubtes per part dels investigadors a l'hora de seguir les polítiques dels finançadors. A més, mentre es discuteix sobre els models idonis per fer sostenible econòmicament aquest sistema han aparegut noves plataformes per publicar que estan sacsejant el panorama de la comunicació científica. En aquest article farem una revisió de l'estat actual de l'accés obert i plantejarem alguns escenaris de futur.

Paraules clau: Accés obert, Comunicació científica

Resumen: Hace unos años el acceso abierto parecía una opción minoritaria que no acababa de establecerse como una alternativa para difundir los resultados de la investigación y avanzar en la carrera académica. El apoyo decidido de las instituciones que financian la investigación ha sido fundamental para que hoy en día el acceso abierto sea una alternativa viable para publicar y además parece que se consolida como la opción de futuro. Sin embargo, aún hay algunas dudas entre los investigadores para seguir las políticas de los financiadores. Además, mientras se discute sobre los modelos idóneos para hacer sostenible económicamente este sistema aparecen nuevas plataformas para publicar que están agitando el panorama de la comunicación científica. En este artículo haremos una revisión del estado actual del acceso abierto y plantearemos algunos escenarios de futuro.

Palabras clave: Acceso abierto, Comunicación científica

Abstract: A few years ago, open access seemed a minority option and it could not be established as an alternative to disseminate research outcomes and allow reserachers to advance in their academic career. The determined support of research funding institutions has been fundamental for open access to be a viable alternative to publish nowadays and it also seems to be consolidated as the option for the future. However, there are still some doubts among researchers to follow funders' policies. In addition, while we are discussing the most suitable models to make this system economically sustainable, new publishing platforms are appearing shaking the landscape of scholarly communication. In this article we will review the current status of open access and propose some scenarios for the future.

Keywords: Open Access, Scholarly communication 


\section{Els inicis de l'accés obert}

A finals de l'any 2001 va tenir lloc a Budapest una trobada d'acadèmics, editors i bibliotecaris sota els auspicis de l'Open Society Institute que va marcar l'inici del que anomenem el moviment de l'accés obert. Cal dir que, abans d'aquesta trobada, ja hi havia iniciatives que apostaven per difondre els resultats de la recerca sense cap restricció [1]. Possiblement la més coneguda d'aquestes iniciatives és l'arXiv, un repositori creat l'any 1991 per Paul Ginsparg per hostatjar les versions enviades a les revistes científiques de l'àmbit de la física, principalment [2].

La trobada a la capital hongaresa va tenir com a resultat el document Iniciativa de Budapest, publicat al febrer de 2002, que estableix l'estratègia per assolir l'accés obert [3] . El que es va plantejar a Budapest és unir una vella tradició, la de compartir els resultats assolits en una investigació, amb un nou mitjà, internet. El resultat d'aquesta unió facilitaria que els resultats de la recerca arribessin a tothom d'una manera ràpida i sense cap trava, ni tecnològica ni econòmica ni legal. D'aquesta manera, naixia el terme accés obert, que no només perseguia que l'accés als resultats fos gratuït, és a dir públic, sinó que a més es poguessin reutilitzar sense cap restricció, llevat del reconeixement de l'autoria i el manteniment de la integritat. Així doncs, el terme obert implica, per una banda, la gratuïtat i, per altra banda, la lliure reutilització. Per assolir aquest objectiu, els autors de la iniciativa varen proposar seguir dues estratègies complementàries que avui en dia han esdevingut les dues vies o els dos colors de l'accés obert. Per una banda tenim la via verda o l'autoarxiu que advoca perquè qualsevol investigador pugui dipositar i difondre una còpia de les seves publicacions mitjançant un arxiu públic que estigui connectat $a$ altres arxius mitjançant un protocol estàndard. Aquests arxius públics reben el nom de repositoris.

La segona estratègia era la de promoure noves revistes que empressin la propietat intel-lectual no per prohibir la utilització dels continguts sinó per facilitar-ne la reutilització a l'hora que es fomentava la transició de les revistes actuals cap a aquest model. L'accés als continguts no quedaria supeditat a cap pagament per tant caldria buscar nous models per fer sostenibles aquestes revistes. En el text de la declaració ja es fa palès aquest repte i no s'aposta per cap model en concret.

Després de la iniciativa de Budapest, l'any 2003 van aparèixer dues declaracions més, la de Bethesda i la de Berlín, que reforçaven les idees plantejades a la capital hongaresa

\section{L'estat actual de la via verda: els autors autoarxiven les seves publicacions?}

La primera estratègia proposada a Budapest per assolir que els resultats es difonguin en obert, apostava per la creació d'uns arxius connectats mitjançant un protocol estàndard on els investigadors poguessin dipositar una còpia de qualsevol publicació i oferissin un accés al públic sense cap mena de restricció. Quinze anys després podem analitzar si aquests arxius, que anomenem repositoris, s'han creat, si els investigadors hi dipositen les publicacions i si s'hi ofereix accés al públic.

Si consultem algun dels directoris de repositoris que hi ha disponibles, podem veure que n'hi ha més de 4500 [4]. La majoria de repositoris són institucionals, és a dir que hi ha una institució 
darrera que vetlla pel seu funcionament i en promou l'ús. A més hi ha repositoris temàtics, és a dir, centrats a recollir i difondre continguts d'una determinada comunitat o disciplina científica, com és el cas de l'arXiV o del PubMed Central. També existeixen els recol-lectors, que són els repositoris que només recullen les metadades d'altres repositoris per tal de facilitar-ne la cerca i augmentar-ne la visibilitat. Un exemple de recol-lector és OpenAIRE, creat per recollir les metadades de repositoris europeus [5]. Per tant, si les infraestructures estan preparades per donar suport a aquesta estratègia caldrà veure si els investigadors les fan servir.

Un dels principals dubtes entre els investigadors és saber si dipositar en un repositori és legal. Generalment quan es publica un article l'editor demana als autors que cedeixin en exclusiva els drets d'explotació o que signin una llicència de publicació exclusiva. Aquesta cessió o llicència pot fer pensar que els autors ja no poden difondre les seves publicacions en altres mitjans, cosa que fa uns anys era ben certa. Tanmateix les cessions o llicències actuals inclouen paràgrafs on s'estipula el que els autors poden fer amb les seves obres i on generalment s'hi indica que poden dipositar una còpia dels articles en un repositori. Però qui es llegeix aquests textos legals abans de signar-los? Cal dir que els editors imposen condicions a l'hora de permetre la difusió dels textos publicats. Les principals restriccions fan referència al format $\mathrm{i}$ al moment per difondre'ls. La majoria d'editors no permeten que es difongui la versió publicada i limiten la difusió a la darrera versió revisada sense la maquetació final, l'anomenada versió de l'autor o postprint. Pel que fa al moment per difondre l'article. s'estableixen períodes d'embargament que ajornen sis, dotze o vint-i-quatre mesos l'accés públic al text complet dipositat en el repositori a partir de la data de publicació. Aquestes condicions es poden consultar en diferents llocs, entre els quals destaca el portal britànic Sherpa/Romeo [6]

Tenim les infraestructures a disposició dels investigadors i la part legal solucionada, així doncs sembla que tot està preparat perquè aquesta estratègia pugui seguir-se. Hom podria esperar que els repositoris estiguessin curulls de documents i per tant quan tinguéssim problemes per accedir a un determinat article sempre tindríem al nostre abast una alternativa oberta. Però la realitat no és aquesta. En els repositoris trobem milers de publicacions però només representen un percentatge petit del total de publicacions científiques. La majoria de repositoris institucionals ofereixen al voltant d'un $20 \%$ de la producció total, encara que algunes institucions assoleixen valors superiors $[7,8]$

La principal raó per tenir aquestes xifres tan baixes possiblement és el fet que els investigadors no veuen el repositori com una eina que els ajuda a fer més visible els seus resultats ni com una alternativa d'accés més enllà de la publicació original. Probablement la majoria d'investigadors suposen que els seus col-legues ja podran accedir als seus textos sense dificultat de la mateixa manera que hi accedeixen ells.

Les institucions, i principalment les biblioteques que generalment gestionen els repositoris, han intentat conscienciar els investigadors de la importància d'oferir una alternativa d'accés en obert. Fins i tot s'han aprovat polítiques o mandats que requereixen el dipòsit, però en la majoria de casos l'incompliment no comporta cap conseqüència o no se'n fa un seguiment. Tanmateix, com veurem posteriorment, sí que les xifres de dipòsit han augmentat quan els principals finançadors de la recerca han establert polítiques més estrictes l'incompliment de les quals pot portar a la pèrdua de l'ajut. 
Una altra dificultat per als repositoris ha estat l'aparició de les xarxes socials d'investigadors que faciliten la difusió dels articles publicats. Aquestes xarxes han tingut un èxit relatiu tot $\mathrm{i}$ que darrerament estan perseguides per les editorials per les infraccions de propietat intel-lectual que es produeixen [9]. Cal remarcar aquí que les restriccions que imposen els editors a l'hora de difondre els textos complets en els repositoris són, com a mínim, les mateixes que s'apliquen en aquestes xarxes. Per exemple, en alguns casos, les revistes hi apliquen períodes d'embargament superiors.

Per tant cal millorar les prestacions dels repositoris i fer realitat l'objectiu plantejat a Budapest, que siguin una alternativa per accedir als resultats publicats. Darrerament han aparegut eines com Unpaywall que faciliten la troballa dels textos dipositats en un repositori gràcies a la connexió amb els identificadors digitals de les publicacions, els DOI.

\section{L'estat actual de les revistes en accés obert: són una opció viable?}

La segona estratègia que es va proposar a Budapest va ser la creació d'una nova generació de revistes que, a més d'oferir els continguts de manera gratuïta, en permetessin la reutilització sense restriccions. Actualment, aquestes publicacions, que reben el nom de revistes d'accés obert, són una realitat i les trobem en pràcticament totes les àrees de coneixement. Si consultem el directori internacional de revistes d'accés obert (DOAJ) podem comprovar que n'hi ha a milers, però també podem veure que no totes en permeten la reutilització de manera clara. En alguns casos les revistes ofereixen els continguts de manera gratuïta però no hi ha cap indicació respecte la reutilització. Cal recordar que en absència de cap avís la publicació es difon mitjançant tots els drets reservats i per tant cal demanar permís expressament per reutilitzar-ne els continguts més enllà de les excepcions previstes per la llei vigent. Aquestes revistes sense indicació de reutilització ni llicència podrien rebre el nom de revistes d'accés públic. De fet són publicacions similars a les que trobem als repositoris on molts cops se'n permet l'accés gratuït però no la reutilització per qüestions de propietat intel-lectual.

Originàriament, una part d'aquestes revistes en accés obert eren d'accés restringit i en molts casos només s'oferien en format imprès. La major part de les revistes que han fet aquest canvi són publicacions universitàries o de societats científiques, tot i que hi ha casos de revistes publicades per les grans editorials científiques que han tingut força repercussió. Entre aquests darrers casos hi ha el de la revista Lingua, publicada per Elsevier, el comitè científic de la qual va dimitir en bloc quan no es va aconseguir arribar a un acord satisfactori amb l'editorial per convertir la publicació en una revista en accés obert. Com a conseqüència d'aquesta dimissió massiva, el comitè editorial va decidir fundar una nova revista en accés obert, Glossa. Així doncs, a més de l'aparició de noves revistes també trobem conversions cap a l'accés obert, tal com es proposava en la declaració de Budapest.

El principal problema que presenten les revistes d'accés obert és la sostenibilitat econòmica ja que publicar té un cost i cal trobar el model de negoci que permeti oferir accés gratuït al text complet. L'altra condició de l'accés obert, el fet de permetre'n la reutilització, ja està solucionada mitjançant l'ús de llicències que indiquen clarament les condicions d'ús. A la declaració de Budapest ja s'apuntava que calia explorar nous models de negoci per les revistes d'accés obert i no es volia apostar per cap en concret. La realitat és que, entre els investigadors, s'ha imposat la idea que l'únic model existent és el de pagar per publicar i s'entén com a revista 
d'accés obert aquella revista on cal pagar per publicar-hi. A favor dels investigadors cal dir que, efectivament, les revistes amb més impacte i que reben més sol-licituds per publicar són les que segueixen aquest model. Però aquest model no és el majoritari entre les revistes en accés obert segons les dades que ofereix DOAJ [10].

També cal remarcar que els principals finançadors de la recerca han assumit els costos d'aquest tipus de publicacions, quan ha calgut, i algunes universitats han creat fons per fomentar aquest model de publicació, com és el cas de la Universitat de Barcelona, primera universitat europea a signar el Pacte per a l'Equitat de la Publicació en Accés Obert al 2010 [11]. Amb l'aparició de fons dedicats a publicar en revistes en accés obert i l'aposta dels finançadors per aquest model, les editorials responsables de revistes d'accés restringit van crear l'anomenat model híbrid. Mitjançant aquest model els investigadors poden fer que un article publicat en una revista d'accés restringit es publiqui en accés obert realitzant un pagament, que generalment assumeixen els mateixos finançadors. Aquest model s'ha estès ràpidament al Regne Unit a conseqüència de l'aposta cap a la publicació en accés obert després de l'informe Finch [12]. Aquest informe, publicat al juny de 2012, va ser encarregat pel govern britànic a un grup de treball per tal d'establir una estratègia per a l'accés obert. La recomanació de l'informe és que cal apostar fermament per la via daurada, és a dir per a la publicació en revistes en accés obert $i$, si no és possible, seguir el model híbrid. Els autors de l'informe reconeixen que aquesta aposta té un cost econòmic alt i que caldrà augmentar la despesa en el període de transició. Després de la publicació de l'informe, la majoria de polítiques de les institucions britàniques va ser la d'apostar per publicar en obert tot i el cost que implicava, especialment quan es publica en híbrid. Les xifres mostren que el cost de publicar mitjançant el model híbrid és més alt que publicar en una revista d'accés obert que tingui una tarifa de publicació [13]. És per aquesta raó que moltes institucions, no només britàniques, estan replantejant-se no donar suport a aquest model o bé limitar-ne el finançament establint una tarifa màxima. Altres institucions que disposen d'ajudes per publicar en accés obert, ja van excloure des de l'inici aquest tipus de finançament per considerar que així no es fomenta que les revistes canviïn de model ans al contrari. A més, es critica que aquests pagaments individuals no tenen repercussió directa en els costos de subscripció i s'ha arribat a acusar les editorials de promoure un doble pagament, el de publicar i el d'accedir als continguts [14]

\section{L'estat actual de les polítiques dels finançadors: Un impuls definitiu cap a l'accés obert?}

A més de les polítiques institucionals destinades a fomentar l'ús dels repositoris i a fer més visible la producció científica d'una institució, l'accés obert està vivint un impuls molt important gràcies a les polítiques de qui finança la recerca. En aquest sentit és remarcable l'aposta feta per la Comissió Europea des del 7è Programa Marc fins ara. L'agost de 2008 es va iniciar un programa pilot pel qual un nombre limitat de projectes finançat per aquest programa marc tenia la recomanació de difondre en obert les publicacions resultants de la recerca mitjançant revistes en accés obert o repositoris institucionals o temàtics. Segons les darreres dades publicades [15], un $67 \%$ dels articles publicats com a resultat dels projectes finançat pel 7è Programa Marc es troben en accés obert. Aquest percentatge s'eleva pràcticament al $75 \%$ si només tenim en compte els projectes que entraven dins del pilot.

A partir de 2014, el programa marc de finançament de la recerca de la Comissió Europea rep 
el nom d'Horitzó 2020 i inclou el requeriment de difondre en obert les publicacions resultants estenent el pilot del 7è Programa Marc a tots els projectes finançats. Com en el cas del pilot, els possibles costos de publicació poden ser inclosos com un cost elegible del projecte. Així doncs, tots els projectes finançats amb diners del Programa Horitzó 2020 tenen l'obligació de publicar en una revista d'accés obert o optar pel model híbrid en una revista d'accés restringit, o bé oferir accés al públic mitjançant un repositori per aquelles publicacions amb accés restringit. De fet, si els investigadors opten per qualsevol de les dues primeres opcions (revista en accés obert o model híbrid) també han d'oferir accés a la publicació mitjançant un repositori. Aquest accés públic a totes les publicacions s'ha d'oferir en un termini màxim de dotze mesos des de la data de publicació per als projectes de ciències socials, arts i humanitats i en un termini màxim de sis mesos per a la resta d'àmbits. Aquests períodes d'embargament són sensiblement inferiors al que ofereixen els editors per defecte i per tant ha provocat que molts investigadors hagin optat pel model híbrid. Les primeres dades publicades sobre el compliment d'aquest requeriment per als projectes del programa Horitzó 2020 mostren que el $72 \%$ de les publicacions es troba en accés obert [16].

A nivell estatal també semblava que hi havia una aposta clara per a l'accés obert quan l'any 2011 es va aprovar la llei 14/2011, la Llei de la Ciència, la Tecnologia i la Innovació [17]. Aquesta Ilei inclou un article que estipula que els investigadors l'activitat de la qual estigui finançada majoritàriament a càrrec dels Pressupostos Generals hauran de difondre en obert qualsevol publicació resultant a través d'un repositori institucional o temàtic. Aquesta difusió s'ha de fer en un període inferior a dotze mesos des de la data de publicació.

La implementació d'aquesta política d'accés obert no es va dur a terme fins a la convocatòria dels projectes del Pla Estatal I+D+I de l'any 2013 i actualment cal oferir accés públic com a màxim sis mesos després de la publicació per a totes les disciplines llevat de les ciències socials, les arts i les humanitats, de la mateixa manera que ha establert la Comissió amb el programa Horitzó 2020.

Els períodes per fer efectiva la política s'han alineat amb Europa però no el seguiment. De fet aquest és el principal problema de la política estatal, la manca d'un seguiment i l'establiment d'unes pautes clares per al compliment com per exemple la creació de codis per identificar els projectes en les metadades dels repositoris. Tot això ha portat a tenir dades poc fiables del compliment. A més, aquestes dades mostren un grau de compliment molt baix, de només el 9\% segons un informe elaborat per la FECYT i publicat al juny de 2016 [18].

Davant de totes aquestes polítiques, què han de fer els investigadors? Des d'aquí jo els faria dues recomanacions: la primera, que triessin lliurement on volen publicar, i, la segona, que sempre es guardessin una còpia de la darrera versió revisada, el que anomenem versió acceptada, versió o manuscrit de l'autor, o, senzillament, postprint. Aquesta darrera versió és la que, en la majoria de casos, es pot dipositar en un repositori i oferir-la en accés públic transcorregut un període de temps. Si els investigadors s'acostumessin a lliurar sempre a llur institució aquesta versió segurament el nombre de registres als repositoris augmentaria i seria molt més fàcil trobar aquest accés alternatiu a la versió publicada accessible només mitjançant un pagament. A més amb aquesta versió es compleix amb totes les polítiques que hem esmentat al llarg del text. 
Les universitats i els centres de recerca, per la seva banda, haurien de fer fàcil tot el procediment de dipòsit i difusió en el repositori. Em consta que la majoria ja ho fan i, a més, han establert automatismes per fer que el temps que cal dedicar-hi sigui el mínim possible. Les institucions també han de comprometre's a analitzar la situació actual de la comunicació científica recollint dades i fent-les públiques per tenir arguments per adoptar polítiques idònies d'accés obert.

\section{El futur de l'accés obert}

Potser en lloc d'escriure del futur de l'accés obert hauria d'escriure sobre el futur de la comunicació científica perquè de fet l'accés obert no és res més que una de les opcions a l'hora de comunicar uns resultats. Sembla clar que cada cop més la difusió dels resultats es fa de manera més oberta ja sigui per vies ja establertes com les revistes o els repositoris o per vies alternatives tipus xarxes socials o portals com Sci-Hub. Hi ha molts països que han apostat clarament perquè tota la producció científica es faci en obert, és el cas dels Països Baixos i Gran Bretanya. Per aconseguir-ho han seguit estratègies diferents, per una banda posant molts diners $i$, fins i tot, assumint els elevats costos del model híbrid, i, per altra, arribant a acords amb les editorials per tal que els diners que fins ara s'han aportat per accedir als recursos serveixin ara per mantenir aquest accés i fer que la nova producció es publiquin en obert.

Aquesta darrera estratègia és la que actualment estan seguint les institucions de recerca a Alemanya mitjançant el Projecte DEAL. A l'hora de renovar les subscripcions d'accés a recursos electrònics han decidit no negociar cap altre acord si no inclou que a partir d'ara tot es publiqui en obert. Sembla que, ara per ara, a l'estat espanyol no hi encara un consens per arribar aquest tipus d'acord a l'hora de negociar i de moment l'objectiu principal en les negociacions continua essent el d'assolir un increment petit en el preus de les subscripcions.

Des de fa un parell d'anys, la Societat Max Planck d'Alemanya també treballa en un projecte per transformar l'actual sistema de comunicació científica canviant els costos actuals d'accés per costos per publicar en accés obert. Aquest projecte es fonamenta a partir d'un informe publicat l'any 2015 [19] que estableix que el cost actual per article és d'uns $5000 €$ si sumem tota la despesa mundial en subscripcions i la dividim pel nombre d'articles que es publiquen, que és d'uns dos milions. Aquesta xifra és molt superior a la mitjana dels preus que es demanen per publicar en les revistes en accés obert que tenen un càrrec per publicar. Aquest fet suggereix que una transició absoluta cap a l'accés obert suposaria un estalvi global teòric d'uns quants mils de milions d'euros. És un estalvi teòric perquè caldria veure si les editorials estarien disposades a disminuir els guanys que tenen actualment [20]. Tanmateix aquest projecte serveix per realitzar un bon exercici per a qualsevol institució de recerca. Les institucions interessades en aquesta proposta cal que obtinguin totes les dades sobre la despesa que realitzen per accedir a recursos de pagament i la que fan per publicar en accés obert, a més de conèixer en detall la seva producció científica: on publiquen els investigadors, en quina proporció apareixen com a autors, quan són els principals autors... Tenir totes aquestes dades ajuden a poder negociar en qualsevol situació. L'objectiu de la Societat Max Planck és que l'any 2020 es comenci a veure aquesta transició.

Per altra banda, mentre les institucions cerquen acords amb les editorials per transformar la seva despesa per accedir als recursos en despesa per publicar, hi ha finançadors que han de- 
cidit estimular una nova manera de publicar els resultats de la recerca i estan desenvolupant plataformes alternatives a les revistes. Podríem dir que aquestes plataformes se semblen als repositoris de preprints, és a dir de publicacions que no han tingut un procés de revisió previ. El repositori d'aquest tipus més antic i conegut és l'arXiv, però darrerament n'han aparegut altres dedicats a altres comunitats científiques com el bioRxiv o el paleoRxiv. L'interès per aquest tipus de repositoris ha augmentat ràpidament $i$ ha fet que les editorials també vulguin oferir aquest tipus d'eina per comunicar els resultats de la recerca d'una manera més ràpida. Una mostra d'aquest interès és la compra per part d'Elsevier del portal SSRN dedicat, principalment, a les publicacions de l'àmbit de les ciències socials.

Però més enllà d'aquests repositoris i alineades amb l'actual moviment de la ciència o la recerca en obert han començat a sorgir plataformes que no només ofereixen la publicació de textos per explicar els resultats obtinguts sinó que ofereixen i fomenten la difusió de dades, codi i qualsevol altre material que els autors considerin adient per sustentar el text. En aquestes plataformes els textos es publiquen sense una revisió per parells prèvia i queden oberts a una revisió posterior en la mateixa plataforma on apareixen les revisions i els suggeriments dels revisors, així com les respostes dels autors. Aquesta revisió oberta ja és un canvi substancial respecte els repositoris de preprints que només oferien la possibilitat de publicar noves versions, en molts casos creades després que el text hagués estat publicat en una revista. A més, l'accés a les plataformes és gratuït i el material publicat es pot reutilitzar sense cap restricció més enllà del reconeixement de l'autoria i el manteniment de la integritat dels continguts. El cost per publicar en aquest tipus de plataformes és inferior a la mitjana de les tarifes de publicació de les revistes d'accés obert que estableixen un càrrec per publicar.

Aquest tipus de plataformes ja està sent utilitzat per Wellcome Trust des de l'octubre de 2016 i ara es posarà en marxa per la Fundació Bill \& Melinda Gates. Ambdues institucions ofereixen als beneficiaris dels seus ajuts de recerca la possibilitat de publicar en aquestes plataformes per difondre els resultats obtinguts. Aquestes plataformes poden esdevenir una alternativa a la publicació en una revista ja que pels finançadors és més important l'impacte que puguin tenir els resultats publicats que el lloc on s'han publicat.

De nou, la Comissió Europea pot jugar un paper molt important si finalment desenvolupa una plataforma de publicació similar i en recomana l'ús als beneficiaris dels projectes de recerca finançats per l'actual programa marc o els següents. Si l'ús d'aquestes plataformes s'entén obligarà a revisar profundament els procediments d'avaluació de l'activitat investigadora que encara es basen, principalment, en premiar on s'han publicat els resultats. La revisió dels sistemes d'avaluació comença a ser una necessitat urgent si es vol apostar cap a la ciència oberta, tal com ha fet la Comissió Europea. 


\section{Conclusió}

Transcorreguts més de quinze anys des de la publicació de la Iniciativa de Budapest podem dir que l'accés obert ha esdevingut una alternativa real a l'hora de publicar i difondre els resultats de la recerca. Encara estem lluny d'assolir l'objectiu final de tenir tots els resultats de la recerca en obert però l'aposta clara de les institucions finançadores n'ha accelerat el procés. Tanmateix encara queda superar un dels principals obstacles: trobar un model econòmic sostenible que permeti mantenir l'accés gratuït cobrint tots els costos de publicació, des de la gestió a les infraestructures.

Per als propers anys s'albiren canvis importants en el sistema de comunicació científica. Veurem si les editorials estan disposades a acceptar un canvi en el model de negoci rebent ingressos per publicar en lloc de rebre'n per accedir als recursos, i si les institucions de recerca es mantenen fermes en l'aposta per l'accés obert i no accepten acords que no el contemplin. I caldrà veure com evolucionen els nous sistemes de publicació que ofereixen la possibilitat de difondre a l'hora resultats en formats diversos amb el repte de revisar-los a posteriori.

Tots aquests canvis s'estan accelerant per l'impuls de la ciència en obert, que no només introdueix canvis en la publicació de resultats sinó que representa un canvi profund en tot el cicle de la recerca i la seva avaluació. Per aquesta raó hem d'estar preparats per assumir i afrontar tots aquests canvis.

\section{Referències}

- [1] P. Suber, Timeline of the Open Access Movement, https://legacy,earlham.edu/ peters/ fos/timeline.htm

- [2] P. Ginsparg, "It was twenty years ago today..., arXiv:1108.2700 [cs.DL], setembre de 2011.

- [3] Budapest Open Access Initiative, http://www.budapestopenaccessinitiative.org/read, febrer de 2002

- [4] Resgistry of Open Access Repositories, http://roar.eprints.org (Dades de novembre de 2017)

- [5] N. Rettberg, and B. Schmidt, OpenAIRE - Building a collaborative Open Access infrastructure for European researchers, LIBER Quarterly 22(3), pp.160-175, 2012, https://doi. org/10.18352/lq.8110

- [6] Sherpa/Romeo, Publisher copyright policies \& self-archiving, http://www.sherpa. ac.uk/romeo/

- [7] R. Morais, J. Bauer, and L. Borrell-Damian, Open Access 2015-2016 EUA Survey Results, June 2017 http://www.eua.be/Libraries/publications-homepage-list/oa-survey2015-2016-results

- [8] R. K. Tillman, Where Are We Now? Survey on Rates of Faculty Self-Deposit in Institutional Repositories. Journal of Librarianship and Scholarly Communication. 5(1), 2017. DOI: http://doi.org/10.7710/2162-3309.2203

- [9] H. R. Jamali, Copyright compliance and infringement in ResearchGate full-text journal articles, Scientometrics (2017) 112:1 241-254. https://doi.org/10.1007/s11192-017-2291-4

- [10] Directory of Open Access Journals (DOAJ), https://blog.doaj.org/2015/05/11/historical-apc-data-from-before-the-april-upgrade/ 
- [11] Compact for Open-Access Publishing Equity, http://www.oacompact.org/compact/

- [12] J. Finch et al., Accessibility, sustainability, excellence: how to expand access to research publications. Report of the Working Group on Expanding Access to Published Research Findings https://www.acu.ac.uk/research-information-network/finch-report-final

- [13] Wellcome Trust, Wellcome and COAF open access spend 2015-16, Juny 2017, https://wellcome.ac.uk/funding/managing-grant/wellcome-and-coaf-open-accessspend-2015-16

- [14] League of European Research Universities, "Christmas is over. Research funding should go to research, not to publishers!", LERU Statement for the 2016 Dutch EU Presidency, Octubre 2015, https://www.leru.org/files/LERU-Statement-Moving-Forwards-onOpen-Access2.pdf

- [15] OpenAIRE, FP7 Statistics, https://www.openaire.eu/fp7-stats

- [16] OpenAIRE, H2020 Monitoring, https://www.openaire.eu/h2020-stats

- [17] España. Ley 14/2011, de 1 de junio, de la Ciencia, la Tecnología y la Innovación. Boletín Oficial del Estado, 2 de junio de 2011, núm. 131, pp. 54387-54455, https://www.boe.es/ buscar/doc,php?id=BOE-A-2011-9617

- [18] FECYT, Informe de la comisión de seguimiento sobre el grado de cumplimiento del artículo 37 de la Ley de la Ciencia, juny 2016, https://www.fecyt.es/es/publicacion/informede-la-comision-de-seguimiento-sobre-el-grado-de-cumplimiento-del-articulo-37-de

- [19] R. Schimmer, K. K. Geschuhn, and A.Vogler, Disrupting the subscription journals' business model for the necessary large-scale transformation to open access, 2015, https:// doi.org/10.17617/1.3.

- [20] V. Larivière, S. Haustein, and P. Mongeon, The Oligopoly of Academic Publishers in the Digital Era, PLOS ONE 10(6): e0127502, 2015.https://doi.org/10.1371/journal.pone.0127502 